\title{
Systems engineering of the Thirty Meter Telescope for the construction phase
}

Scott Roberts, John Rogers, Hugh Thompson, Konstantinos Vogiatzis, Douglas MacMartin, et al.

Scott Roberts, John Rogers, Hugh Thompson, Konstantinos Vogiatzis, Douglas MacMartin, Eric Wilde, Mitchell Troy, Byoung-Joon Seo, Carl Nissly, "Systems engineering of the Thirty Meter Telescope for the construction phase," Proc. SPIE 9150, Modeling, Systems Engineering, and Project Management for Astronomy VI, 91500V (4 August 2014); doi: 10.1117/12.2056870

Event: SPIE Astronomical Telescopes + Instrumentation, 2014, Montréal, Quebec, Canada 


\title{
Systems engineering of the Thirty Meter Telescope for the construction phase
}

\author{
Scott Roberts*a, John Rogers ${ }^{\mathrm{a}}$, Hugh Thompson ${ }^{\mathrm{a}}$, Konstantinos Vogiatzis ${ }^{\mathrm{a}}$, Douglas MacMartin ${ }^{\mathrm{a}}$, \\ Eric Wilde ${ }^{\mathrm{a}}$ Mitchell Troy ${ }^{\mathrm{b}}$, Byoung-Joon Seo ${ }^{\mathrm{b}}$, Carl Nissly ${ }^{\mathrm{b}}$ \\ ${ }^{a}$ TMT Observatory Corporation, 1111 South Arroyo Parkway, Suite 200, Pasadena, CA 91105, USA \\ ; ${ }^{b}$ Nasa Jet Propulsion Laboratory, Pasadena, CA
}

\begin{abstract}
This paper provides an overview of the system design, architecture, and construction phase system engineering processes of the Thirty Meter Telescope project. We summarize the key challenges and our solutions for managing TMT systems engineering during the construction phase. We provide an overview of system budgets, requirements and interfaces, and the management thereof. The requirements engineering processes, including verification and plans for collection of technical data and testing during the assembly and integration phases, are described. We present configuration, change control and technical review processes, covering all aspects of the system design including performance models, requirements, and $\mathrm{CAD}$ databases.
\end{abstract}

Keywords: TMT, Thirty Meter Telescope, systems engineering

\section{INTRODUCTION}

\subsection{Introduction}

The TMT International Organization (TIO) includes five partner countries with participation from multiple organizations and industrial partners in the design and implementation of the 32 observatory subsystems, and their assembly and integration at the 13 North site on Mauna Kea. A significant challenge for TMT Systems Engineering is to enable multiple international partners and suppliers to work on these self-contained sub-systems, whilst having confidence that when they are integrated as a system they will meet the system level performance requirements.

TMT Systems Engineering has developed processes to support this distributed development, while maintaining the ability to respond and trade cost and schedule with requirements, budgets and performance at the system level. An ongoing challenge is to ensure that system engineering delivers products of industry or aerospace quality without invoking burdensome/expensive processes. In response to this, TMT takes a pragmatic approach to processes and selects those that offer best 'value for money'. These minimize risk and deliver a quality product whilst providing a realistic framework for partners and suppliers to work within. Examples include invoking only select parts of external standards as requirements, matching the scope of change management activities to the significance of the change, developing TMT processes that draw on existing standards and industry best practices. A key challenge is to maintain the ability to react to problems, run analysis models, re-allocate budgets, update the agreed system configuration without getting bogged down or overwhelmed. This requires both clearly understood and efficient processes established across the project.

The key approaches that we have adopted include the following:

- Maintain a clear flow-down from science cases to system and subsystem requirements, enabling a clear understanding of trade-offs, and an ability to make changes as needed in an efficient manner.

- Maintain a logical system decomposition that can describe each sub-system in terms of requirements that are consistent with system performance and interfaces that clearly define responsibilities, functions and designs.

- Provide an efficient change process that supports appropriate review and efficient approval cycles at the needed project level.

- Document and agree the configuration of the system and subsystems in a manner that is clear and enables efficient change when required.

*sroberts@tmt.org; phone 1250 363-8314; www.tmt.org

Modeling, Systems Engineering, and Project Management for Astronomy $\mathrm{VI}$, edited by George Z. Angeli, Philippe Dierickx, Proc. of SPIE Vol. 9150, 91500V

(c) 2014 SPIE $\cdot$ CCC code: $0277-786 X / 14 / \$ 18 \cdot$ doi: $10.1117 / 12.2056870$ 
- Organize the Project and Systems Engineering team such that there is direct interaction between SE and partner organizations, while maintaining the appropriate reporting relationships between the TMT and Partner work package managers.

- Maintain requirements and interfaces in a common DOORS database, providing all project stakeholders access to the database and its products.

- Maintain a common observatory geometry database that accepts models from subsystem teams and incorporates them in to a common Digital Mock Up of the observatory. Make this database available to stakeholders within the project.

- Provide a verification and acceptance test process that emphasizes the importance of verification and preshipment acceptance of subsystems before shipment to the observatory.

This paper provides details of the processes that TMT Systems Engineering has implemented to address these issues.

\subsection{TMT System Design Overview}

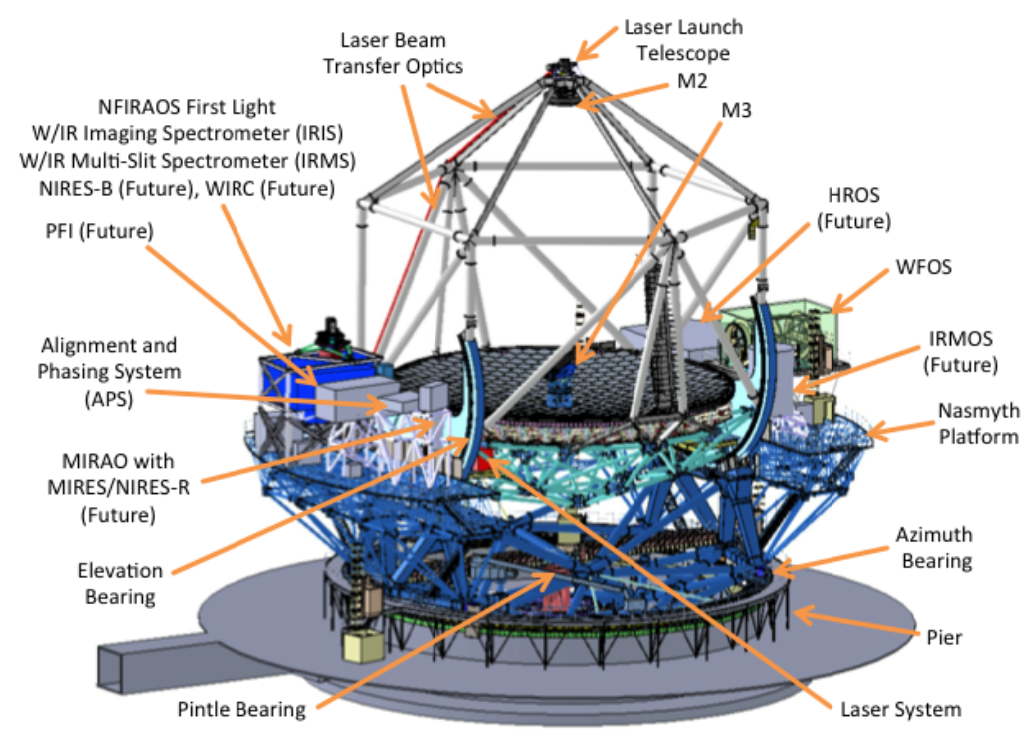

Figure 1 - The Thirty Meter Telescope

The science reach of TMT is made possible through the groundwork of years of experience within the TMT partner communities, development of a unique combination of advanced technologies, innovative design and systems engineering. The key observatory design choices include:

- A $30 \mathrm{~m}$ diameter, filled-aperture, finely-segmented pupil maximizing near-diffraction-limited performance, high contrast, and uniform point spread function (PSF).

- A steerable tertiary mirror to address multiple instruments quickly, increasing observational efficiency, and enabling key science cases involving rapid follow-up of targets of opportunity and transient objects.

- A multi-conjugate adaptive optics system that will provide a unique first-light combination of diffraction limited correction in $\mathrm{J}, \mathrm{H}$, and $\mathrm{K}$ bands, a large and astrophysically useful field, excellent image uniformity and stability, and extensive sky coverage (greater than 50 percent).

- Telescope and instrument designs with minimal optical elements and cooled instrument environments providing low throughput losses and low thermal background.

- A suite of highly efficient and stable instruments addressing not only the Detailed Science Cases, but providing broad capabilities to support unforeseen science that will be enabled by TMT.

TMT employs a fully developed system engineering methodology including requirements engineering, performance modeling, and cost and schedule engineering. Since the inception of the project in 2003, the TMT Observatory has been 
engineered and optimized as a system with defined system architectures and designs that optimize the observatory performance within cost and schedule constraints, and with acceptable risk. Science drives system requirements in a rigorous and traceable manner. This facilitates design vs. cost vs. schedule vs. science tradeoffs to be evaluated. The hierarchy of the TMT system decomposition from the full system to subsystems and components is guided by a corresponding hierarchy of requirements documents and documented interface specifications between subsystems. The configuration of the design is controlled by a formal configuration management system that manages evolution and change of technical, cost and schedule elements through a Change Control Board (CCB) managed by the System Engineer and chaired by the Project Manager. This requirements and configuration engineering process is completed by verification procedures that will certify the performance and design conformity of received items.

System performance is assured by extensive system modeling and simulation and by tests of prototype or delivered items. Modeling codes are benchmarked by applying them to existing observatories and observatory systems. This benchmarking has been carried out using measurements performed at the W. M. Keck Observatory and the Canada France Hawaii Telescope.

All project documentation is centrally archived in the TMT Document Control Center (DCC) which currently contains more than 31,000 documents in 7400 collections serving 800 users including project staff, collaborator staff, Board and SAC members and industrial suppliers working under contract to TMT in all partner countries. The DOORS ${ }^{\circledR}$ object oriented requirements database contains the TMT linked requirements and interface control definitions.

\subsection{System Decomposition}

To simplify requirements and interfaces and to allow clear and complete allocation of functions, we decompose the observatory into 32 subsystems divided among Facilities, Telescope, Instrumentation, and Operations Design. Each subsystem is uniquely defined by its Design Requirements Document (DRD) and interfaces are established to ensure proper connections and cooperation between the subsystems. The boundaries between subsystems are set to promote and enable independent, concurrent development, fabrication, and verification of the individual subsystems.

Figure 1 shows the visible observatory subsystems. The Telescope is built around the Telescope Structure holding the mirrors (M1 Optical System, M2 and M3 Systems), as well as the actuators, sensors, and most of the electronics of the Mount Control and M1 Control Systems (MCS and M1CS), Alignment and Phasing System (APS), and Telescope Controls. Supporting subsystems are the Optical Cleaning and Coating Systems, Optics Handling Equipment, and Test Instruments with their Controls. The Observatory Safety System and Engineering Sensors, are also Telescope subsystems.

First light instrumentation is split between the facility AO system NFIRAOS, the Laser Guide-Star Facility (LGSF), and the AO Executive Software (AOESW) and the near-diffraction limited and seeing limited instruments: the Infra-Red Imaging Spectrometer (IRIS), Infra-Red Multi-Slit Spectrometer (IRMS), and the Wide-Field Optical Spectrometer (WFOS). Additional systems supporting the science instruments are the NFIRAOS Science Calibration Unit, and the instrumentation cooling system.

The observatory software subsystems belong to Operations Design: Common Software, Communications and Information Systems, Data Management System, Executive Software, Science Operations Support and Data Processing Systems. The Site Conditions Monitoring System is also part of Operations Design.

Facilities include the Enclosure, Summit Facilities, the road leading to the observatory at the $13 \mathrm{~N}$ site, and the Headquarters in Hilo.

Both the organization and Work Breakdown Structure (WBS) of the project reflect the system decomposition. The project consists of Project Management plus four departments corresponding to the major subsystem groups: Facilities, Telescope, Instrumentation, and Operations Design.

\subsection{TMT Systems Engineering Responsibilities}

Systems Engineering (SE) is part of the observatory Project Management function, and the Systems Engineering Group Leader reports directly to the TMT Project Manager. SE is responsible for the technical performance of the observatory. SE has the responsibility and authority to:

- Establish and maintain the technical configuration and architecture of the observatory.

- Establish and maintain the observatory technical requirements and interfaces. 
- Establish and maintain system models, performance estimates and budgets.

- Establish and maintain the observatory test and evaluation strategy against requirements and interfaces.

- Manage and execute the observatory system level test process.

- Assess and manage the observatory technical risk assessment.

- Maintain an evaluation of the system technical status against requirements.

- Regularly report, including at system level review, systems engineering status, and the TMT system level technical status.

\subsection{TMT Systems Engineering Organization}

The key challenges and planned solutions for TMT systems engineering organizational challenges are described in Table 1.

Table 1 - TMT System Engineering Organizational Challenges and Solutions

\begin{tabular}{|l|l|}
\hline Challenge: & Solution: \\
\hline $\begin{array}{l}\text { Achieving common } \\
\text { understanding of SE } \\
\text { processes across partnership }\end{array}$ & $\begin{array}{l}\text { Clear guidance on system engineering expectations for key milestones during system } \\
\text { development through Product Data Package Definition document. Systems } \\
\text { engineering presentations at institutes, systems engineering Wiki pages. }\end{array}$ \\
\hline $\begin{array}{l}\text { Maintaining consistency of } \\
\text { engineering practices across } \\
\text { partnership }\end{array}$ & $\begin{array}{l}\text { Establishment of a standard review process with SE the default Chair for reviews. } \\
\text { Clearly defined Configuration Control Plan, Product Data Package Definition, } \\
\text { Document Approval Matrix. Use of templates and examples to guide engineering } \\
\text { practices. Close working relationships with partner organizations. }\end{array}$ \\
\hline $\begin{array}{l}\text { Establishing well defined } \\
\text { working relationships across } \\
\text { partnership }\end{array}$ & $\begin{array}{l}\text { Clarify SE role and responsibility within project. Establish efficient working } \\
\text { relationships with subsystem teams. Ensure that working relationships respect the } \\
\text { direct reporting lines between the project office and partner teams. }\end{array}$ \\
\hline
\end{tabular}

The systems engineering organization chart is shown in Figure 2. This chart shows a subset of the partner organizations and of the TMT departments for illustrative purposes. The TMT Systems Engineering Group Leader reports directly to the TMT Project Manager. Planned hiring dates are shown for positions that are not currently filled.

As shown by the dotted line relationships, SE works directly with the TMT PO Work Package Managers, as well as the partner organizations. However, there is no direct reporting relationship with systems engineering for these activities. The coordination of activities is directed by the TMT PO Work Package managers, in coordination with TMT Systems Engineering. 


\section{TECHNICAL CONFIGURATION AND ARCHITECTURE}

\subsection{Challenges and Solutions}

The key challenges and planned solutions for the management of system technical configuration and architecture are described in Table 2.

Table 2 - Technical Configuration and Architecture Challenges and Solutions

\begin{tabular}{|c|c|}
\hline Challenge: & Solution: \\
\hline $\begin{array}{l}\text { Maintaining control of the } \\
\text { design without } \\
\text { introducing barriers to } \\
\text { suppliers making design } \\
\text { progress. }\end{array}$ & $\begin{array}{l}\text { Change control of most design information is done in a single location (Configuration } \\
\text { Index Document, CID) that allows design documents to evolve between design } \\
\text { milestones without being bogged down in TMT process. Regular communication } \\
\text { between TMT and suppliers, shared design tools and other concurrent engineering } \\
\text { practices minimize the risk that changes will be rejected when the design is documented } \\
\text { and agreed in a CID. }\end{array}$ \\
\hline $\begin{array}{l}\text { Understanding effects of } \\
\text { change request at each } \\
\text { level of the design. }\end{array}$ & $\begin{array}{l}\text { Technical change requests affecting requirements are developed in DOORS and by using } \\
\text { the traceability tools provided, the effects of system level changes on sub-system } \\
\text { requirements are easily visible. }\end{array}$ \\
\hline
\end{tabular}

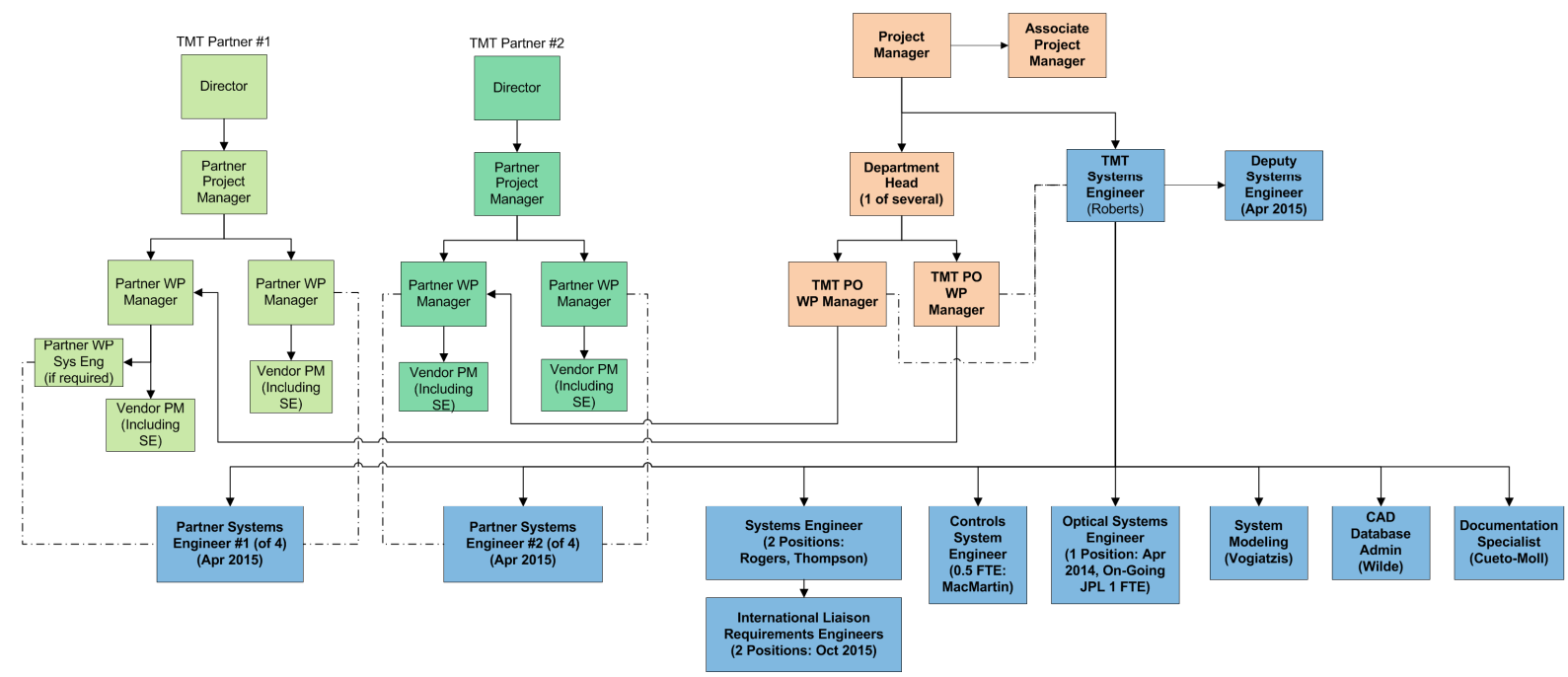

Figure 2 - Systems Engineering Organization Chart

\subsection{Configuration Control}

The objectives of the TMT Project change management and configuration control processes are to:

- Define the configuration of the TMT system, both current and past.

- Manage Configuration Items (CIs), ensuring appropriate definition, review and authorization of change.

- Provide auditable evidence of stakeholder review and approval of CIs.

The scope of the configuration control includes all aspects of the project including science capability; cost; schedule; technical; environment, safety and health; quality assurance. The Configuration Control Plan document covers:

- The CR process and procedures, including the Change CCB.

- The technical review process as it applies to system configuration. 
- Document configuration control processes for the TMT Project Document Control Center (DCC) including Draft (DRF), Release (REL), and Change Controlled Release (CCR) documents.

- The application of configuration control processes to products of:

- DOORS requirements database.

- Project Management Control System (PMCS).

- $\mathrm{CAD} / \mathrm{PDM}$ drawing and solid model configuration control.

- TMT financial systems.

- Software source code.

- Manufactured hardware.

\subsection{Document Types and Configuration Items}

The TMT Project defines three fundamental designations for documents: Draft (DRF), Release (REL), and Change Controlled Release (CCR). DRF documents are uncontrolled and can be changed at will by the owner. DRF documents never define the configuration of TMT.

The two types of released/controlled documents (REL and CCR) enable a clear process for proposing change from one side, and agreeing from the other. Regular communication between TMT and suppliers, shared design tools and other concurrent engineering practices minimize the risk that changes will be rejected when the design is documented and agreed in a CID.

REL documents are issued by the author or a specific partner organization, and to not themselves include indication of TMT Project Approval. REL documents can define the configuration of the system through reference in a Configuration Index Document (CID, see later), which is a CCR document. When REL documents are to be included in CIDs, the document is signed by the author or by an organizational representative. CCR documents are signed to indicate direct and formal approval by the project.

A Configuration Item (CI) is the fundamental structural unit of a Configuration Management System. All TMT CIs are held on the DCC as CCR documents. The TMT project utilizes several databases to manage information that is included in project CIs, including the DOORS requirements database, the Project Management Control System (PMCS), and the Open Plan Schedule software. In many cases project CIs are generated from the source database as PDF reports. This ensures that the database and the CI are identical. Requirement documents are an example of this. These source databases must have revision control processes to enable recording and management of the mapping between database and $\mathrm{CI}$ content.

\subsection{Configuration Index Documents}

TMT utilizes Configuration Index Documents (CIDs) to record the configuration of the TMT system and subsystems. The CID is a CCR document that contains a list of REL and CCR documents that define the current agreed and approved configuration of the subsystem. Documents referenced in CIDs include Requirements; Interfaces; Design Documents including design descriptions, detailed designs, engineering models, analysis reports; Safety documents; Reliability documents; Manufacturing documents; Assembly and Integration Documents; Operations and Maintenance Plans; and Verification documents.

\subsection{Change Requests}

A formal change request is required for the modification of the TMT configuration as documented in CCR documents. Usually a Change Control Request form is required to initiate a change. The level at which approval occurs for change requests is related to the scope and significance of the proposed change. Depending on the significance of the change, approval authorities can include Cost Account Managers; Department Heads; and Project Manager, with and without the Change Control Board (CCB). The needed level of approval is described in the Configuration Control Plan. A CCB action is required for the most significant changes. The CCB considers changes for documents that are indicated as CCB required in the Document Approval Matrix, or for changes that have any of the following characteristics: cost impact of $\$ 100 \mathrm{k}$, schedule impact of 3 months, or significant risk (as assessed by the SE). 


\subsection{Data Package Deliverables}

The TMT Data Package Deliverables Document specifies the project documentation that is to be reviewed at each major review milestone. The document includes a description of the expected content of the document, and indicates whether the documents are to be REL or CCR releases. Templates are available for the standard document deliverables.

\begin{tabular}{|c|c|c|c|c|c|c|c|c|}
\hline Section & Title & Description & 产 & 产 & 器 & $\frac{\alpha}{\alpha}$ & $\frac{\alpha}{\infty}$ & 选产 \\
\hline \multirow{2}{*}{$\begin{array}{l}\text { Requirements - sub- } \\
\text { system requirements }\end{array}$} & Level 2 DRD & Contains the design requirements for the leve 2 sub-system & $\mathrm{R}$ & c & c & c & c & c \\
\hline & Level 3 DRDs & $\begin{array}{l}\text { Contains the design requirements for key level } 3 \text { assemblies that make } \\
\text { up the level } 2 \text { sub-system (as agreed with Systems Engineering) }\end{array}$ & & c & c & c & c & c \\
\hline $\begin{array}{l}\text { Requirements - } \\
\text { Interfaces }\end{array}$ & ICDs* & $\begin{array}{l}\text { Contains numbered interface statements for each interface between the } \\
\text { sub-system anc other level } 2 \text { sub-systems identified in the TMT } N^{\wedge} 2 \\
\text { diagram. Similar documents to be produced within sub-system for } \\
\text { internal interfaces between level } 3 \text { componen's that make up the sub- } \\
\text { system. }\end{array}$ & & $\mathrm{c}^{1}$ & C & $c^{2}$ & $c^{2}$ & $\mathrm{c}^{2}$ \\
\hline $\begin{array}{l}\text { Design - Design } \\
\text { Description }\end{array}$ & $\begin{array}{l}\text { Design Description } \\
\text { Document }\end{array}$ & $\begin{array}{l}\text { Each sub-system shall produce a design description document } \\
\text { corresponding to the conceptual, preliminary and final design reviews } \\
\text { as well as the delivered configuration. The design document is a } \\
\text { summary document prepared specifically for each milestone. As a } \\
\text { minimum it should contain the following: } \\
\text { - a description of the sub-system, i.e. an overview of the system that }\end{array}$ & $\mathrm{R}$ & $\mathrm{R}$ & $\mathrm{R}$ & $\mathrm{R}$ & $\mathrm{R}$ & $\mathrm{R}$ \\
\hline
\end{tabular}

Figure 3 - Excerpt from TMT Product Data Package Definition showing document type and description plus the expected document release level for each major design phase

\subsection{Document Approval}

The TMT Document Approval Matrix defines the project CCR and REL documents, along with the approval requirements for these documents. Some CCR documents always require a CCB action for approval. Document signatures indicate concurrence (often by several signees) and approval (always by one signee). Additional signatures may be required on documents as the system or subsystem passes project milestones. This is indicated in the Figure by either "YES" indicating that signatures are required for all phases, or by a phase designator meaning that a signature by that authority is required before the indicated milestone is passed.

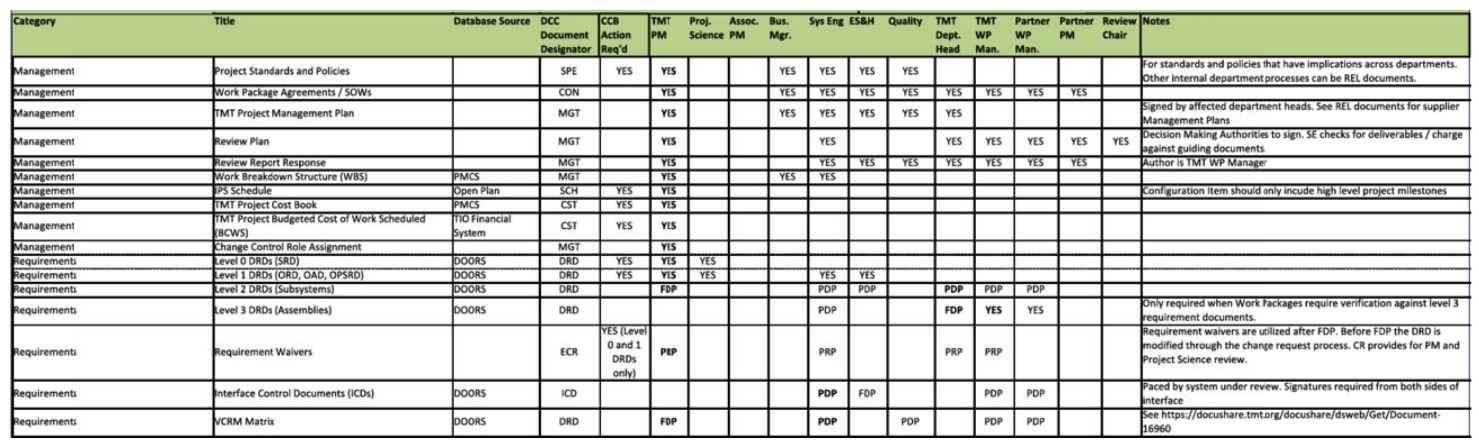

Figure 4 - Excerpt from TMT Document Approval Matrix showing the required signatures for release of CCR documents

\section{REQUIREMENTS AND INTERFACES}

\subsection{Requirements and Interface Management}

The key challenges and planned solutions for the management of requirements and interfaces are described in Table 3 .

Table 3 - Requirement and Interface Challenges and Solutions

\begin{tabular}{|l|l|}
\hline Challenge: & Solution: \\
\hline $\begin{array}{l}\text { Maintaining control of requirements and } \\
\text { interfaces at the system and subsystem level. }\end{array}$ & $\begin{array}{l}\text { Maintain requirements and interfaces in DOORS, and create } \\
\text { traceability between requirements at various levels. }\end{array}$ \\
\hline Efficiently manage requirements with small & $\begin{array}{l}\text { Work directly in DOORS instead of import/export from Word or } \\
\text { Excel. Implement requirements change proposal process in DOORS }\end{array}$ \\
\hline
\end{tabular}




\begin{tabular}{|l|l|}
\hline systems engineering team. & in a manner that is consistent with the Configuration Control Plan. \\
\hline $\begin{array}{l}\text { Ensure project stakeholders have visibility } \\
\text { into the requirements and interfaces } \\
\text { traceability and meta-data. }\end{array}$ & $\begin{array}{l}\text { Provide stakeholders throughout the project direct access to } \\
\text { Requirements, Interfaces, their traceability and metadata in DOORS } \\
\text { via DOORS Web Access and JPL TraceTree web based tool. }\end{array}$ \\
\hline
\end{tabular}

The TMT Requirements Structure and basic DOORS schema has been reported previously ${ }^{1}$. TMT is making a transition from developing requirements in Word or Excel, and maintaining parallel versions in DOORS, to working directly in DOORS and outputting documents to PDF (via Word). We encountered many difficulties and significant SE staff overhead in trying to maintain parallel versions in DOORS and Word/Excel including inevitable differences between versions, and managing parallel changes from multiple departments or partners. We have taken a rigorous approach to defining our DOORS procedures, document module views and attributes, filters and permissions, to enable us to work directly in DOORS with the TMT departments and partner technical teams. This work is in its early stages but it is already showing significant advantages. Some of the key additions we are making in our DOORS implementation include:

- Verification Cross-Reference Matrices, and Verification Activities are maintained in doors, using separate Verification Activity modules with links to the DOORS requirement modules.

- Maintaining a list of Applicable and Reference Documents including standards in DOORS, and linking these with requirements. This allows visibility into where and how modifications to documents will affect the requirements.

- The requirement change request process is supported directly in DOORS using attributes to hold proposed CR changes. This process allows any TMT staff member to propose a change directly in DOORS rather than indirectly by e-mail or Issue Tracker.

- Adoption of the NASA/JPL Trace Tree tool gives excellent visibility to the requirements and links between requirements across the project.
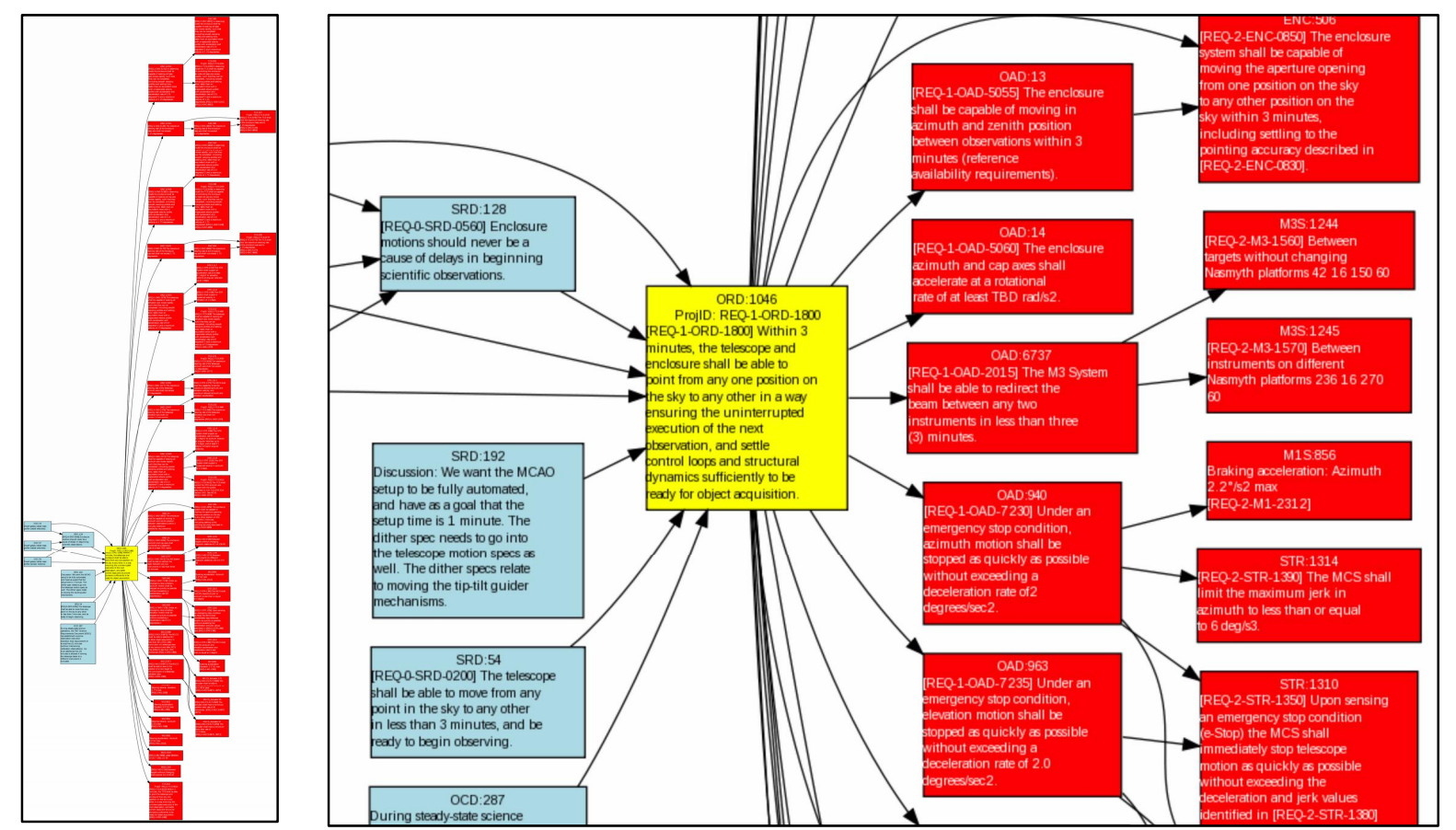

Figure 5 - JPL Trace Tree Tool Visualization of Requirements Traceability, showing the full traceability of a complex requirement on the left, zoomed in on the right 


\section{SYSTEM MODELS, PERFORMANCE ESTIMATES AND BUDGETS}

\subsection{Challenges and Solutions}

The key challenges and planned solutions for the management of system models, performance estimates and budgets are described in Table 4.

Table 4 - System Models, Performance Estimates and Budgets Challenges and Solutions

\begin{tabular}{|l|l|}
\hline Challenge: & Solution: \\
\hline $\begin{array}{l}\text { Current modeling results may not represent the } \\
\text { agreed design of the system. }\end{array}$ & $\begin{array}{l}\text { Ensure that modeling results are traceable to Configuration Index } \\
\text { Documents entries. Ensure that model description documents } \\
\text { clearly define the input data and modeling code versions used. } \\
\text { Ensure that both input and output data are linked to and } \\
\text { consistent with requirements and budgets. }\end{array}$ \\
\hline $\begin{array}{l}\text { Modeling results may become obsolete without } \\
\text { our knowledge, especially when system designs } \\
\text { are being developed in a distributed partnership. }\end{array}$ & $\begin{array}{l}\text { Record modeling assumptions in terms of references to CID } \\
\text { documents. Review models when considering updates to CIDs. } \\
\text { Record and store modeling inputs, outputs and code. }\end{array}$ \\
\hline
\end{tabular}

\subsection{Modeling Documentation and Models}

In order to maintain insight into system models, TMT maintains modeling manuals that document the inputs, modeling procedures, and outputs of the models. These documents give visibility into where the input data for models is derived from, and what the current estimated performance of the system is. An example of this is the JPL Optical Modeling Error Manual that describes the inputs, calculations and output performance estimates for seeing limited image quality error budget terms.

\subsection{Model Archiving and Storage}

Storage of modeling inputs, code and outputs is a challenging problem, since models can change significantly between estimates, and the relationship of inputs and outputs of various models can change. Software repositories such as RCS, CVS or GIT were considered but rejected because the software development paradigm that they support is dissimilar to the requirements of a model data and code repository. Instead we have decided to store our models in a Samba file system, using a directory structure for model inputs, code and outputs for each step of the modeling process. A directory tree will store all inputs, outputs and code for a particular performance estimate. Successive estimates will use a separate directory tree structure, even if large parts of the model are identical. This allows us the greatest flexibility to store models, and also to go back and run previous versions of models. As described in the previous sections, the version of model utilized for a performance estimate and the modeling manual document will be recorded in the CID.

\subsection{Budgets}

The key budgets tracked at the system level Observatory Architecture Design Requirements Document ${ }^{2}$ include:

- Reliability and Availability of system and subsystems

- Heat Dissipation and Power Consumption

- Image Size Error Budget for Seeing Limited Operations

- Wavefront Error Budget for Adaptive Optics Operations

- Pointing Error

- Pupil Shift

- Plate Scale Stability

- Mass

- Primary Mirror (M1CS) Actuator Range of Travel

- Vibration 
In general these budgets allocate resources or performance based on higher level requirements. The budget allocations are traced to subsystem allocations. These relationships are recorded via links in the DOORS database, allowing TMT systems engineering visibility to understand consequences of not meeting performance related requirements, and the ability trade performance across subsystems.

\subsection{Seeing Limited Error Budget}

An example of budget tracking and re-allocation is provided by the seeing limited error budget, shown in Figure 6 . This budget is in units of normalized point source sensitivity, or PSSn ${ }^{3}$. The total allowable degradation in PSSn is $15 \%$, meaning that the sensitivity of TMT will be $85 \%$ that of a "perfect" telescope with the TMT aperture. The figure shows two bars for each term, the budget allocation for each term on the left, and the current best estimate on the right. Based on recent high fidelity modeling of mirror and dome seeing we have been able to reduce the budget allocation for these terms. However, more recent modeling of wavefront sensor errors shows that we are not meeting our budget allocations. Therefore we plan some re-allocation in a future release, and this will require updates to subsystem requirements that will be identified through DOORS traceability reports.

\subsection{System Performance Models}

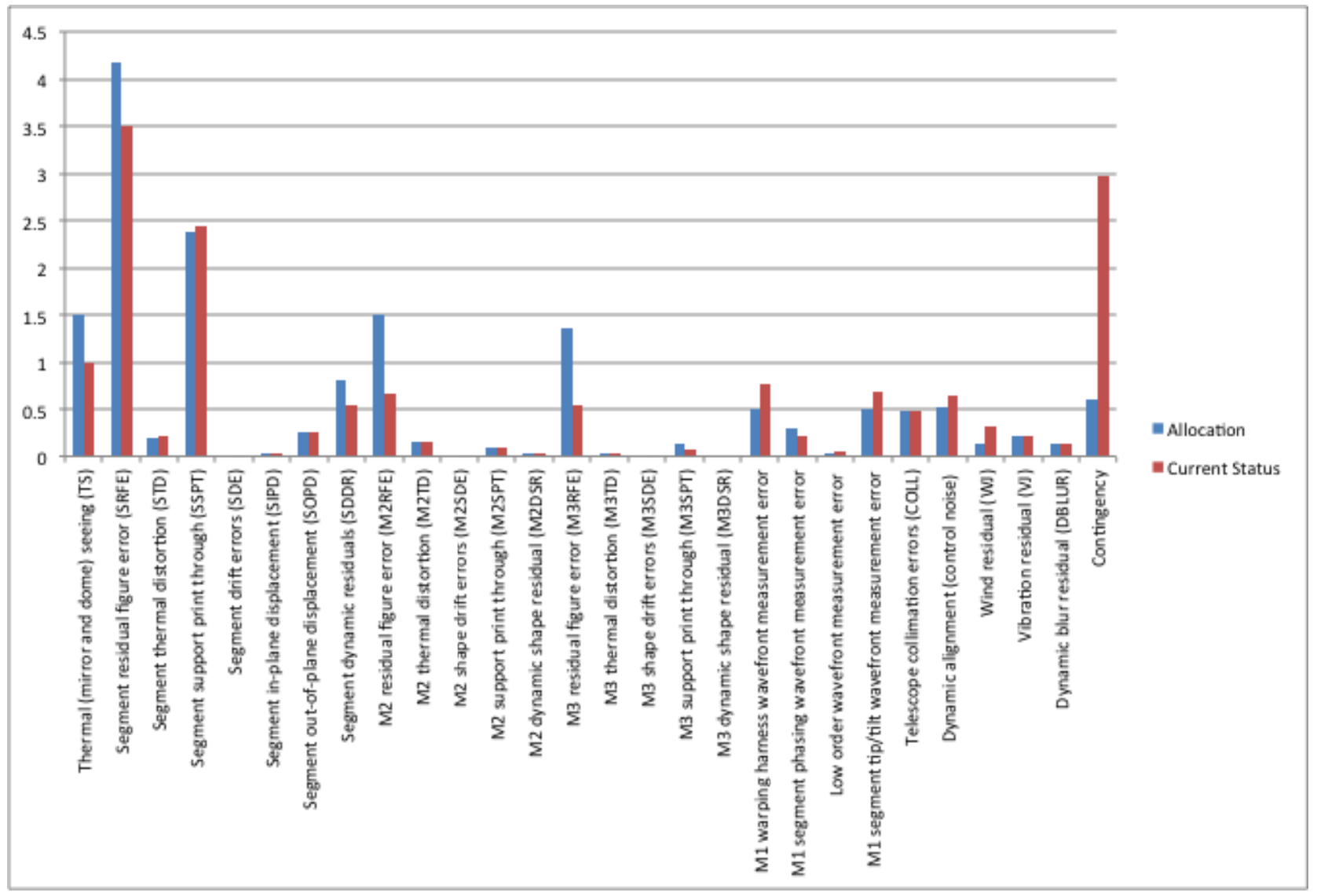

Figure 6 - Current status of seeing limited error budget in \% PSSn. The total budget is $15 \%$

\section{CAD PRODUCT DATA MANAGEMENT}

\subsection{Challenges and Solutions}

The key challenges and planned solutions for the management of system models, performance estimates and budgets are described in Table 5. 
Table 5 - CAD Product Data Management Challenges and Solutions

\begin{tabular}{|l|l|}
\hline Challenge: & Solution: \\
\hline $\begin{array}{l}\text { Having a system that supports different } \\
\text { ways of working across the partnership; } \\
\text { designers working within TMT on in-house } \\
\text { manufacturing drawings and also suppliers } \\
\text { working within their own system but } \\
\text { delivering models to TMT. }\end{array}$ & $\begin{array}{l}\text { TMT has a vault structure that supports different types of users. A } \\
\text { dedicated working area allows sub-system teams to use the CAD vault } \\
\text { as a true product data management environment with change } \\
\text { management and workflows. A system level area stores the top level } \\
\text { assemblies and constituent parts, but only manages traceability and } \\
\text { version history. }\end{array}$ \\
\hline $\begin{array}{l}\text { Confirming that the designs generated by } \\
\text { remote sub-system teams meet the current } \\
\text { requirements. }\end{array}$ & $\begin{array}{l}\text { TMT maintains solid models that are used to check requirements } \\
\text { relating to space allocation, geometry and clearances. These are } \\
\text { updated via TMT CR process (and hence are representative of current } \\
\text { requirements) and are used to check sub-system models. }\end{array}$ \\
\hline $\begin{array}{l}\text { Having sufficient version control and } \\
\text { revision history within the TMT PDM } \\
\text { system without burdening suppliers with } \\
\text { detailed rules for part numbering, } \\
\text { configuration management. }\end{array}$ & $\begin{array}{l}\text { TMT tracks version history and configuration at the level of top TMT } \\
\text { assemblies, traceability and configuration management at the part level } \\
\text { is handled by supplier's own internal processes, approval of supplier's } \\
\text { design data is performed as part of our CID process. }\end{array}$ \\
\hline $\begin{array}{l}\text { Enabling dispersed teams access to the } \\
\text { latest designs that constitute the TMT } \\
\text { observatory. }\end{array}$ & $\begin{array}{l}\text { TMT maintains a 'digital mock up' of the observatory. This is a } \\
\text { SolidWorks assembly model containing the latest design models that } \\
\text { make up the observatory. All sub-system teams have access to this } \\
\text { single source of data. }\end{array}$ \\
\hline
\end{tabular}

\subsection{Sub-System Models}

In general, solid models, assembly drawings and part drawings are provided for all TMT sub-system equipment. The generation of individual sub-system models and drawings is the responsibility of the various Sub-System Groups and their suppliers. The process and rules for providing and generating these models is given in the TMT CAD Model and Drawing Management Plan.

Once approved, these models are stored in the Enterprise PDM database and organized in the relevant folder corresponding to the WBS element. The top assembly models and drawings will be stored under the appropriate TMT part number and placed under version control. Lower level part and sub-assembly drawings may also be placed under version control as agreed with the responsible Sub-System Group.

\subsection{Space Envelope Models and Drawings}

TMT System Engineering produces space envelope/volume allocation models and drawings for all equipment mounted either to the telescope or within the enclosure. These show the volume allocated to the equipment in addition to basic interface and optical information. They are stored in their respective sub-system area of the Engineering area with a drawing number and placed under version control.

\subsection{Geometry Drawings}

TMT System Engineering produces geometry drawings of the observatory as required, for example instrument positions on the Nasmyth platforms. These are stored in the Engineering area of the database with a drawing number and placed under version control. 


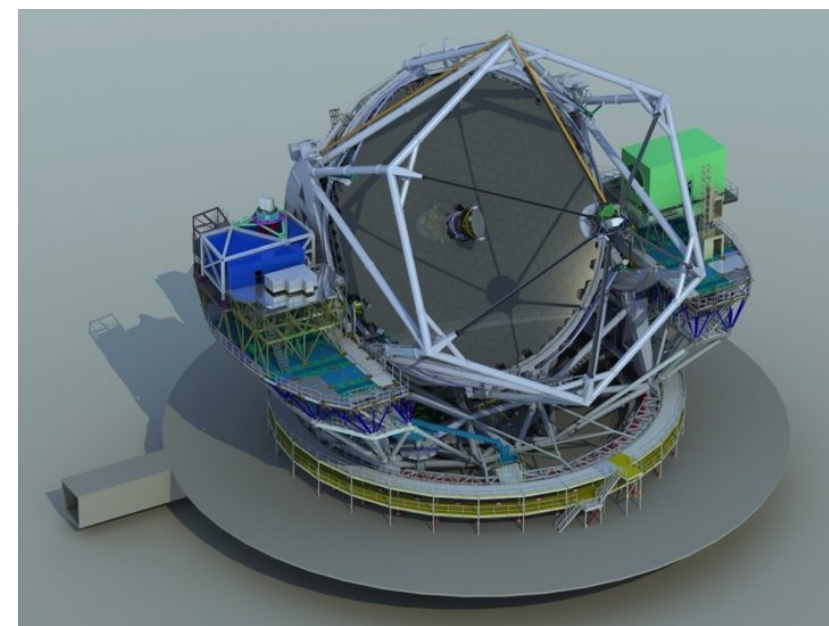

Figure 7 - DMU Image

\subsection{Interface Drawings}

Interface drawings between sub-systems will be stored in the Engineering area of the PDM system. These are produced as agreed by either the Sub-System Groups or system engineering.

\subsection{Digital Mock-Up}

The Digital Mock Up contains models representing the agreed configuration of the observatory. The principle is that it contains the latest agreed design. It contains the TMT master geometry model, sub-system models as supplied and approved by the Sub-System Groups and space envelope/volume requirement models produced by system engineering. To minimize model size, different configurations are produced that include a reduced set of sub-system models. The DMU is coordinated and controlled by system engineering via revision letter.

\section{VERIFICATION AND ACCEPTANCE TESTING}

\subsection{Challenges and Solutions}

The key challenges and planned solutions for the management of verification and acceptance testing are described in Table 6.

\section{Table 6 - Verification and Acceptance Testing Challenges and Solutions}

\begin{tabular}{|l|l|}
\hline Challenge: & Solution: \\
\hline $\begin{array}{l}\text { Identifying potentially } \\
\text { challenging requirements and } \\
\text { planning verification early } \\
\text { enough to mitigate any risk. }\end{array}$ & $\begin{array}{l}\text { Plan verification for each requirement at an early stage and identify verification } \\
\text { activities at appropriate milestones (PDR, FDR etc.) to build confidence that } \\
\text { design will meet its requirements and identify problems at an early stage. }\end{array}$ \\
\hline $\begin{array}{l}\text { Maintaining visibility and control } \\
\text { of system performance as } \\
\text { verification results are generated. }\end{array}$ & $\begin{array}{l}\text { Plan and track verification in DOORS and using traceability to help understand } \\
\text { and manage system performance: } \\
\text { - System budgets and performance requirements } \\
\text { - Sub-system requirements and sub-system verification results }\end{array}$ \\
\hline
\end{tabular}

\subsection{Overview}

TMT has adopted an incremental verification process that includes Verification Activities (VAs) against individual requirements. There is a defined set of VAs for each requirement. Verification occurs at defined Verification Milestones (VMs) throughout the development of the system. The agreement of the set of VAs occurring at defined VMs for each 
requirement is documented in the Verification Cross Reference Matrix (VCRM). Verification Plan and Verification Procedure documents define the agreed verification process for requirements. Verification Reports are generated for each VA by the partner or vendor team and delivered to the TMT WP Manager. TMT Systems Engineering and the Quality Assurance Officer review the Verification Reports and either approve or reject them. Upon approval, Verification Reports are signed as per the Document Approval Matrix.

\subsection{Acceptance Testing}

Acceptance testing includes executing the set of VAs associated with the acceptance milestones such as PSR or FAR, as defined in the Work Package Document. Acceptance also depends on the successful completion of the VAs scheduled at milestones prior to the Acceptance Milestone. The criterion for technical acceptance of a subsystem or assembly is that the set of VAs for each requirement and interface is either verified and agreed based on System Engineering acceptance of a Verification Report, or formally waived via a Requirements Waiver. Generally, failed verification tests against VAs are repeated after redesign/rework until passed and approved by TIO. Requirement Waivers may also be granted, with the consequence that the associated VAs may be waived or modified. Also, Verification Procedure Waivers may be granted that permit a modification to the test procedure.

\subsection{Verification and Acceptance Roles and Responsibilities}

In general any verification activity will have the team responsible for the Assembly \& Integration of the system under test presenting the verification to the party responsible for accepting that system.

For TMT Level 1 verification, it is the TMT Systems Engineering team that is responsible for the Verification Activity. TMT Project Management will be responsible for acceptance (or rejection) of each Level 1 requirement verification.

In the case of Level 2 verification, the subsystem manager is responsible for the completion of each Verification Procedure and presenting these reports to TMT Systems Engineering for acceptance at the agreed Verification Milestones for that subsystem.

\section{RISK MANAGEMENT}

The key challenges and planned solutions for the management of risk are described in Table 7.

Table 7 - Risk Management Challenges and Solutions

\begin{tabular}{|l|l|}
\hline Challenge: & Solution: \\
\hline $\begin{array}{l}\text { Ensuring that risks and threats to the project are } \\
\text { identified, made available to project stakeholders, } \\
\text { and mitigated to an acceptable level. }\end{array}$ & $\begin{array}{l}\text { TMT maintains risk registers at the system and subsystem levels, } \\
\text { and holds regular reviews at both levels. Mitigation plans are } \\
\text { identified and progress is tracked in the risk register. }\end{array}$ \\
\hline
\end{tabular}

TMT formalizes the management of risk in the following three ways:

1. Risk analysis at lowest level of WBS in the cost estimate to generate risk adjustment. The rationale for the included risk adjustment is included as a narrative in the cost book.

2. Risk analysis in schedule development to address critical paths and other schedule risks.

3. A Risk Register employed for formal project-wide system level risk identification, assessment and retirement.

The TMT Project has implemented a formal Risk Register process to identify risks that are assessed to be threats to the system technical performance, cost, or schedule and manage those risks through risk reduction actions and other types of mitigations. TMT Systems Engineering maintains a system level risk register on the Project Management Control System (PMCS). In addition to the project risk register, each subsystem team keeps a subsystem risk register. Regular risk register meetings, scheduled quarterly, review both the subsystem and system risks registers. During these meetings, existing risks are reviewed, new risks may be added, and existing risks may be retired. Risks may be promoted or demoted between the subsystem and system risk registers. An example risk register entry is shown in Figure 9 and the historical progression of risk entries is shown in Figure 10. 


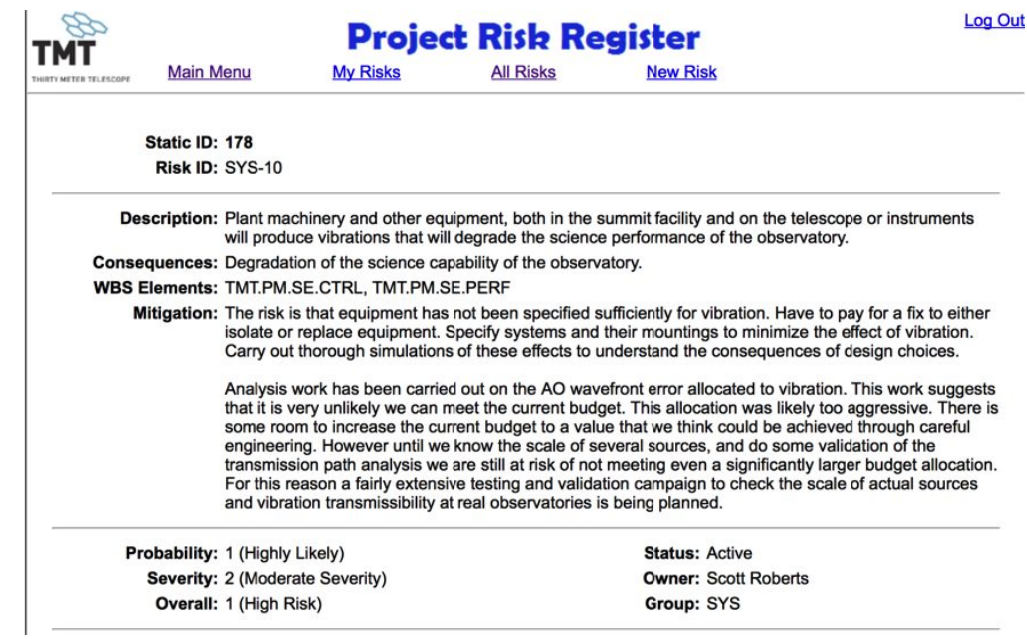

Figure 9 - Example Risk Register Entry

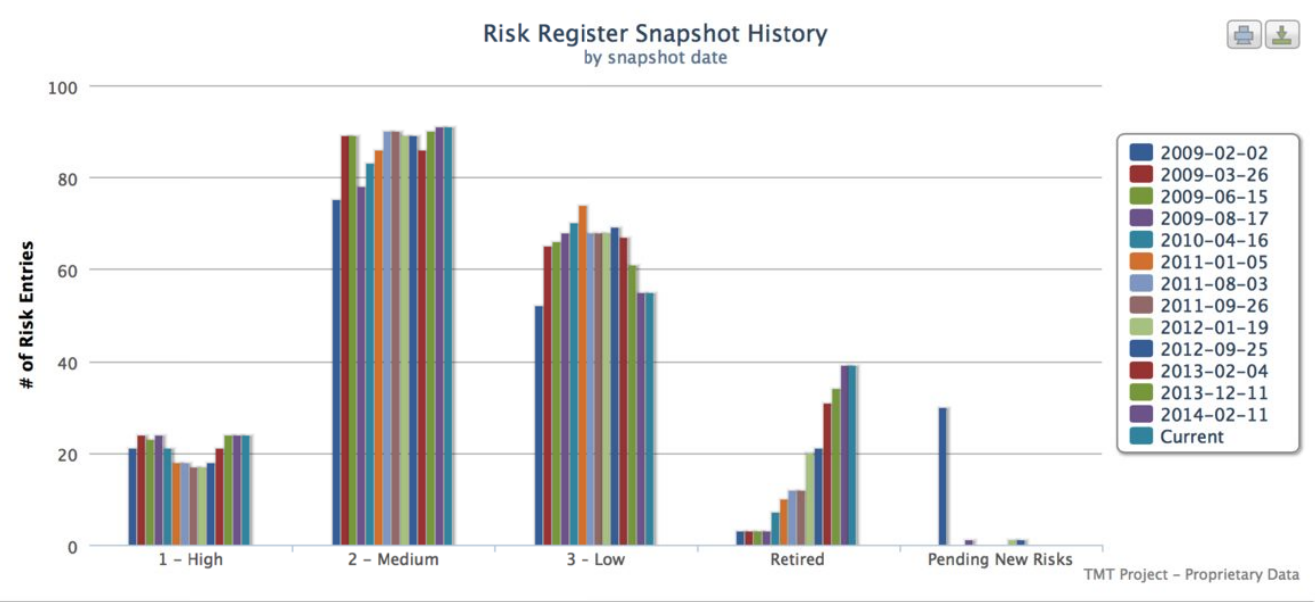

Figure 10 - Risk Register History

\section{TECHNICAL ASSESSMENT AND EVALUATION}

The key challenges and planned solutions for the management of verification and acceptance testing are described in Table 8.

Table 8 - Technical Assessment and Evaluation Challenges and Solutions

\begin{tabular}{|l|l|}
\hline Challenge: & Solution: \\
\hline $\begin{array}{l}\text { Ensuring that the subsystem and system } \\
\text { designs are appropriately developed. }\end{array}$ & $\begin{array}{l}\text { TMT has clearly defined expectations for technical and programmatic } \\
\text { status at each review milestone. The review process has been } \\
\text { standardized with systems engineering as the default review chair. }\end{array}$ \\
\hline
\end{tabular}

A formal design review process has been established to evaluate the state of development and implementation of the observatory, its subsystems and critical components. The standard reviews for a TMT subsystem include Feasibility, Conceptual Design, Preliminary Design, Final Design, Production Readiness, Pre-Shipment, and Final Acceptance. The review process involves committee review of the documentation with questions and responses on a discussion tool forum prior to the face-to-face review meeting. Reviews assess technical performance and maturity, as well as the compliance of the design and end product with the stated requirements and interfaces. The reviews also serve as 
configuration audits, establishing that design and construction activities correspond to the accepted documentation. The review committee report may lead to direction for corrective actions on the system, which may be supported by CRs.

The review process is defined by two primary documents, TMT Reviews: Definitions, Guidelines and Procedures, and TMT Product Data Definition. A Review Plan Document that defines the scope, agenda and committee charge, defines each review. The findings of the review are documented in a Review Report, produced by the review committee. The Review plan and report are signed and controlled as defined in the Document Approval Matrix. A Review Report response is written by the Work Package manager for the system under review, and is approved by the TMT Project Manager. This report defines how the review findings will be addressed.

\section{SUMMARY}

We have presented an overview of the TMT project, illustrating the complexity of both the technical systems and the challenges of performing systems engineering within a distributed partnership. Within this context we have outlined the key challenges and our planned mitigations and solutions in conducting the systems engineering of the construction phase. Following from these, we have described the processes that TMT systems engineering will utilize for the construction phase in the areas of managing the system technical configuration and architecture; requirements and interfaces; system models, performance estimates and budgets; CAD product data management; verification and acceptance testing; risk management; technical assessment and evaluation.

\section{ACKNOWLEDGEMENTS}

The TMT Project gratefully acknowledges the support of the TMT collaborating institutions. They are the Association of Canadian Universities for Research in Astronomy (ACURA), the California Institute of Technology, the University of California, the National Astronomical Observatory of Japan, the National Astronomical Observatories of China and their consortium partners, and the Department of Science and Technology of India and their supported institutes. This work was supported as well by the Gordon and Betty Moore Foundation, the Canada Foundation for Innovation, the Ontario Ministry of Research and Innovation, the National Research Council of Canada, the Natural Sciences and Engineering Research Council of Canada, the British Columbia Knowledge Development Fund, the Association of Universities for Research in Astronomy (AURA), the U.S. National Science Foundation and the National Institutes of Natural Sciences of Japan.

\section{REFERENCES}

[1] George Z. Angeli, Scott Roberts, and Konstantinos Vogiatzis, "Systems engineering for the preliminary design of the Thirty Meter Telescope," Proc. SPIE 7017, 701-704 (2008)

[2] TMT Observatory Architecture Document, TMT.SEN.DRD.05.002, < http://www.tmt.org/documents $>$

[3] Byoung-Joon Seo, Carl Nissly, George Z. Angeli, Brent Ellerbroek, Jerry Nelson, Norbert Sigrist, and Mitchell Troy, "Analysis of Normalized Point Source Sensitivity as Performance Metric for Large Telescopes," Applied Optics 48, pp. 5997-6007 (2009) 